\title{
Traditional classrooms transformed into modern school environments through collaborative action research
}

\author{
Kapachtsi Venetia, Kakana Domna-Mika \\ Department of Early Childhood Education, University of Thessaly, Volos, Greece \\ Email address: \\ bekapah@gmail.com (K. Venetia),dkakana@uth.gr (K. Domna- Mika)
}

To cite this article:

Kapachtsi Venetia, Kakana Domna-Mika. Traditional Classrooms Transformed into Modern School Environments through Collaborative Action Research. International Journal of Elementary Education. Vol. 3, No. 3, 2014, pp. 58-64. doi: 10.11648/j.ijeedu.20140303.12

\begin{abstract}
Collaborative teaching approach has confused teachers in Greece, who although generally argue in favour of this, however, state that they are unable to incorporate it into their daily teaching practice. Thus, collaborative action research, as a form of training, has been implemented to a group of teachers in order improvement to be achieved. The opinions and feelings of the participants are presented in the following article. Analyzing the facilitator's observation notes and the participants' interviews seems that action research has triggered a change in pupils' learning process. Additionally, teachers exchanged ideas, expressed themselves without hesitation and adopted innovations. According to the researcher, teachers' hard and lonely work is supported through the collaborative action research. This kind of training focuses on their needs, takes place at their own school, while the member of the University and the researcher undertake the support work. With this effort, the classroom can be transformed into a modern school environment, more active, experiential and collaborative one.
\end{abstract}

Keywords: Curriculum, Collaborative Approach, Improvement, Teachers, Action Research

\section{Introduction}

The debate on curricula covers many aspects and parameters concerning their epistemological framework, such as the goal setting, the content, the teaching approaches and methods and the evaluation as well. The current curriculum for compulsory education (5-15 years) has been established in Greek schools since the academic years 2003-04 [11] and proposed new methodological approaches that promote collective activity, a cooperative spirit and interaction. Thus, working in groups effectively is considered to be the focus of teaching strategies.

Nevertheless, it is known that collaborative approach has confused teachers, who although generally argue in favor of this, however, state that they aren't absolutely ready to implement and incorporate it into their daily teaching practice. Research data confirm the trend, that although teachers internationally evaluate collaborative learning and teaching very positively, it seems however that the information available on the practices of teachers and the ways in which group collaboration approach is applied to the natural context of the classroom is limited [13, 17, 19]. So the focal point of a successful collaborative approach is regarded to be the teacher, because he/she will determine the extent of implementation, the integration and utilization of these changes and innovations, transforming an officially designed curriculum to everyday practice. The issue of an effective and efficient teachers' training seems to be very important.

According to the above, the main purpose of this study was to highlight teachers' experiences, difficulties and positive aspects of collaborative teaching and learning, after having participated in experiential activities developed in the framework of collaborative action research. The research was planned and implemented in a school unit of primary education with five teachers who participated in this effort. The aim of teacher's participation in the action research was their professional development.

\section{Models of Teachers' Professional Development}

Various approaches or models of teachers' professional development have been developed based on certain concept of education and learning.

Initially, the technological approach was developed, based on the positivist epistemology. According to this theory, teachers through instrumental rationality use techniques arising from structured knowledge in order to solve practical and technical problems [9, 28]. Teachers 
simply adopt the technical teaching and "apply the principles to ensure effective learning" [9] (p.84).

According to the second approach, the interpretative one, the construction of knowledge is achieved by teachers, through their personal involvement and collective analysis of authentic statements $[9,28]$. Teachers are involved in a process of narration of their concerns and experiences and through description and review, they construct and reconstruct knowledge about teaching and life. In this way they systematize their personal educational theory. The objections on this model, from the positivist point of view, arise from "the weakness of this approach to produce generalizations or to provide criteria for the verification of theoretical references" [9] (p.126), pointing out that educational theory could not be based on interpretations of teachers.

The third approach of professional development, the critical one, is directly related to practice, focuses on the moral and political dimension of education and highlights from inside the thinker - critical analysis of educational dilemmas, alternative teaching options [28]. This approach is based on critical pedagogy [14] and in accordance with its view, the act is action and not construction and calls the teacher to take responsibility, to contribute not only to his change but to the improvement of society in general. The aim of this approach is not the production of rules and guidelines for their application in educational practice, as the context and teachers' needs are different. What matters in this approach, is the research method which enhances the reflection on educational practices and problems. "The teacher is interested in connecting theory to practice, wonders for a variety of educational issues that arise daily, puts them to the test, guides the research process in the classroom and he/she is responsible for the implementation of the results" [19] (p.18). Action research, which is based on the critical approach contributes to the professional development of teachers and tends to turn educational practice (schooling) to more profound pedagogical process, through which there is motivation of individuals to complex problems either, social and economical or cultural one [22]. Its purpose is regarded to be not only the change of teaching practices and school improvement, but the improvement of the whole educational system as well. It's "a form of self - reflective research undertaken by participants, in social situations, in order to improve educational practices and understand practices and situations that occur" [8] (p.162). Action research has its basis on Aristotle's view, according to which the "crucial point that leads to truth is not the theoretical knowledge, but knowledge in practice" [5] (p.407). The term "praxis" used by Aristotle, contrasts the term "theory", defining practice as the art to act in the existing conditions in order to change them. Teachers face problems, which are specific in each situation. So, it is necessary to define the problem, that "in a complex environment demands a type of thought, arising from reflection and then to carry out the most suitable performance" [5] (p.408).
Action research in school can actually be performed: a) by an individual teacher (individual action research), b) by a group of teachers in collaboration with a researcher or a member of a University (collaborative action research) [1, $2,6,24]$ or c) in a broad form by members of a University in collaboration with schools (school wide action research) [30]. It is used for the development of the curriculum, the professional development, the change of the teaching practices and the development of cooperation within schools $[9,10,23]$.

Collaborative action research, on which we focus in this paper, is a collaborative effort between researchers and teachers, in order to bring together knowledge and experience respectively, bridging the gap between research and practice in order to solve educational problems [21]. The characteristics of collaborative action research are defined by Day (2003) as: "review and reflection, collegiality and cooperation" (p. 31). Collaborative action research can be seen as a strategy for teachers' professional development, when "there is a practice to be improved, a circular spiral design of action, observation of the plan and thinking”. Each of these steps are associated with each other and at the end participants are involved actively [9] (p.220). The existence of a facilitator with some knowledge in research and with ability in interpersonal relations is necessary [25]. He/she could bring teachers in contact with the theoretical framework of action research and reflection. Additionally he/she could encourage and support teachers to become analytical and contemplating [18].

Many researchers, either individually or in collaboration with universities undertook collaborative programs in schools in order to improve teachers' practices.

Smylyan [31], in collaboration with the University of Hampshire and Oakland, introduced in two secondary schools, a two-year program with 10 participating teachers. The results showed that although the teachers did not see immediately visible results in improvement, they started to become more receptive to change" (p. 69).

Caro-Bruce and McCreadie [7] implemented collaborative action research with eight participants in Madison Metropolitan School. The results showed that teachers showed increasing interest, introduced new teaching methods and became more professional (p.38)

Lally and Scaife [24] from the University of Sheffield, introduced in secondary school collaborative action research model, so-called "wardrobe model". Their purpose was to add to teachers' wardrobe, new clothes (practices, techniques, culture change). According to their findings, the participants managed, through collaborative action research, to create collaborative environment, improve their relationships and introduce new practices" (p. 324).

The researchers, Ambrose, Lang \& Grothman [1] implemented collaborative action research with four secondary school teachers and their findings showed that through this effort, "teachers discovered their strengths and weaknesses and improved themselves during the teaching process"(p.61). 
In Norway, Helstad [15] from the University of Oslo worked with a team of teachers and developed collaborative action research to improve the writing ability of students in various subjects. She points out the importance of collaborative action research in supporting teachers (p.53).

Recently in Croatia, the Centre for Teacher Education developed collaborative programs in schools. In the collaborative programs Milovic \& Cain (2009) stress the consultant's role in identifying problems (p.102).

Vermeulen, Tordoir \& Kroon [32] point out the significance and the importance of tools in collaborative action research with the introduction of "double loop»), as a way to analyze the process of action research (p.90).

In Cyprus, collaborative action research was developed with a teacher who aimed to be improved in classes with different learning abilities [2]. The results showed that the benefits were double, as the teacher improved teaching practices and the researcher had the experience of the facilitator.

In Greece, collaborative action research program was introduced into a nursery school and three Primary schools [12]. In this program, they focused on methodological tools of action research-calendars, photos, notes. According to the results, teachers deepen their practices when they use "friendly tools"(p.65). They also mention the role of the facilitator as a core professional and scientific assistance in collaborative action research (2009). Apart from it, University of Thessaly participated in a research program studying the educational transition from the traditional to collaborative teaching model through action research process. The participating kindergarten teachers, through action research, overcame what prevented them from teaching collaboratively. The conclusion of this research was, that in any training effort teachers' educational style should be taken into consideration [20].

\section{Methodology}

\subsection{General Methodological Framework}

The present research was based on data of two case studies of school units of primary education in an urban and a rural area in Thessaloniki, in the Northern part of Greece.

Self-evaluation of the two units was seen as a way of gathering information from the subsystems of the two schools (students, teachers, two headmasters and parents) in order to use the results to be used for further actions for the improvement of the weaknesses of the organizations $[4,25]$. The results of self-evaluation of the two school units showed, that learning and teaching is the factor that needs the most improvement. Specifically, both parents and students desired the introduction of new methods, less homework, creative and enjoyable projects and attractive teaching. Teachers and the two principals wanted their professional development in order to teach more effectively. So based on these data we developed collaborative action research, by creating a network of communication between the team of teachers and the academic community. The researcher took the active and dynamic role of the facilitator in order to contribute to the feedback of the educational research process [3]. A faculty member of the University had the scientific responsibility of the training effort as well [27]. It is worth mentioning that the collaborative model of professional development in both schools was based on the priorities of teachers. The collaborative method of teaching has been the centerpiece of this training effort.

\subsection{Specific Methodological Framework}

Initially, for the development of the training process, we took into consideration some basic conditions. We should have formed the group of teachers who would be involved in this effort, after school, within the specific context and environment of their own school. We chose their own place because "opportunities of high quality such as co-teaching, collaboration among teachers and observation are offered" [26] (p.28). In addition, our aim was to develop an equal partnership between teachers and the research team and a cordial and friendly atmosphere as well. It is worth mentioning, that the attitude of the headmasters of the two school units towards this was really positive.

So, within the one of the two school units and for six months, collaborative action research was developed, with participants only five women teachers who participated in a voluntary basis. The teachers A., E., M. N. and Mer. taught in different grades of primary school. The group was facilitated by the researcher Venetia Kapachtsi and supported by the professor of the University of Thessaly, Domna-Mika Kakana.

From the first moment, it was agreed that the meetings would take place every 15 days, but during the process they became weekly. There were in total 15 meetings while the researcher visited the schools on a weekly basis for discussion and individualized support to teachers.

At the first meetings, teachers described their earlier experiences and the fears concerning the cooperative approach. They had some objections regarding the effectiveness of teamwork and some potential problems as «the big fuss and the «leading figures» who suppress the others. From the beginning, we tried to create a new cooperative culture within the research group where everything could be said and discussed. Our aim was not the ready answers and solutions to the problems but an interaction and exchange of experiences and initiatives.

Also, at the first meetings we presented the theoretical framework of collaborative approach to the participants, we discussed the principles of a project and the theme of reflection. In this way, the teachers could learn and create a common basis for discussion. Additionally, we proposed some planning changes in classrooms as it is an essential element for the creation of cooperative learning environment. Apart from these, the participants experimented with the formation of the first groups, which 
were set up in some classes freely, while in some classes with teachers' intervention. In any case, throughout the duration of the training program, the teachers exchanged experiences, by implementing parallel corrective actions in classrooms, they discussed and proposed different options.

After the pedagogical framework (reorganization of space, heterogeneous groups, division of roles, duties and responsibilities in groups) had been largely achieved, teachers expressed a desire to penetrate deeper into the teaching context, by working cooperatively different units of the courses of Greek language, mathematics and environmental studies.

Afterwards, we presented the methodological tools of action research to the participants and we suggested them to start observation among their colleagues in classroom, in order to make an assessment of collaborative teaching. Generally, the participants were very enthusiastic with the whole effort and they tried their best in order to be improved.

The model of the collaborative action research is presented in diagram 1

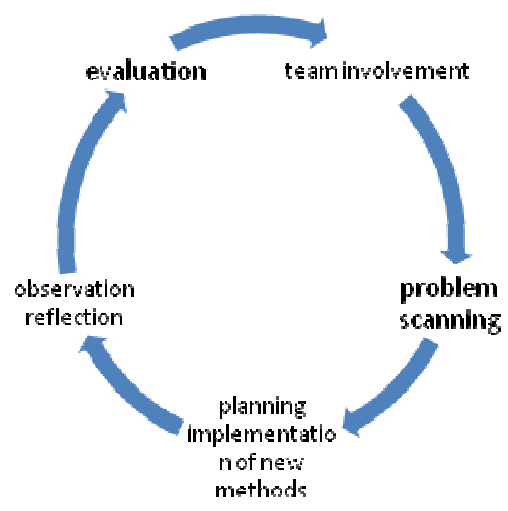

Diagram 1. Collaborative Action Research

\subsection{Data Collection and Analysis}

Based on the method of triangulation, a variety of data collection techniques were used in order the results of the collaborative action research to be checked (Mason 2003). More specifically: questionnaires with open questions given to pupils and parents at the conclusion of the study, interviews taken by the five participants, and the researcher's field notes, kept at the meetings and at the observations in classrooms, provided an opportunity to study thoroughly past events in order to gain insights about the action research. For the purposes of this paper, however, we will focus only on the opinions and feelings of the participants. The research analysis initially followed the phase of coding, then creating categories of analysis (basic and related) and finally interpreting in a reflective way.

The codification of the research in this phase into basic and related categories refers to "the analytical process of grounded theory" [16] (p. 80), a type of case study, details of which are incorporated in this study. "The basic or core categories of the analysis of the data is the result of an interactive relationship between research questions and data" [27] (p.271).

The first basic category "collaborative action research as a form of training", correlated to research question, whether action research is a trigger for changes in the teaching process and the introduction of new teaching practices. The second category of "impact of the training effort" was formed by the research question about the impact of new practices to parents and students. The first basic category and the second one as well, were supported by related categories, based on the data collected. The categories are given in (Table 1) below.

Specifically, in the basic category "collaborative action research as a form of training» the related subcategories «changes in the teaching process, students' attitude towards new practices (from the teacher's point of view) and the change of teachers' bond" emerged from the analysis of the interviews of the participants.

In the second basic category emerged three subcategories, related to the impact of the training effort to students, parents, and the facilitator. These relative subcategories emerged from the analysis of responses to the questionnaires, given to students and parents, but also from the analysis of the facilitator's observation notes and teachers' interviews.

Table 1. The codification of the data.

\begin{tabular}{|c|c|}
\hline Basic categories & Related Categories \\
\hline $\begin{array}{l}\text { A. The collaborative action } \\
\text { research as a form of training }\end{array}$ & $\begin{array}{l}\text { a. changes in teaching process } \\
\text { b. Students' attitude towards new } \\
\text { practices (teachers' point of view) }\end{array}$ \\
\hline & c. change of teachers' bond \\
\hline B. The impact of the training effort & $\begin{array}{l}\text { a. to the students } \\
\text { b. to the parents } \\
\text { c. to the facilitator }\end{array}$ \\
\hline
\end{tabular}

\section{Results-Conclusions}

\subsection{Data Collection and Analysis}

Analyzing the facilitator's observation notes and the five participants' five interviews seems that action research has triggered a change in the learning process. Particularly, this change was achieved by the introduction of the collaborative approach through: a) an individual focus on teachers' needs, b) the development of the process of reflection and c) the support from the University team.

Specifically, according to the participants' notes, action research was: "a very productive process during which we express our personal experiences and reflections", "it was an effort starting from the base, from the teacher", "it was a kind of psychoanalysis and relaxing process. We could say our problems and difficulties and find a solution".

Teacher A said that "the seminars are typically impersonal. A lecturer shows some slides to a large audience but there is no discussion or support, for what the teachers really need at an individual level. On the contrary, this training effort focuses on the individual level. I think, that after these 
meetings, all cleared up in my mind".

Teacher E regards action research as "a chance of exchanging experiences, the best solution for facing problematic situations and innovation and for exchanging ideas". She further states: "through the discussions we understood some things better, we got new ideas".

Teacher Mer. said that "within the group I started thinking whatever I experimented in class. We discussed everything in the meetings and together we analyzed the problems. I applied alternative solutions".

Finally, the views of teachers $\mathrm{N}$ and $\mathrm{M}$ converged on the point, that action research "is an essential training because it focuses on the needs of specific teachers". Teacher M said: «It is really the best way, so as to face the problems of class. Even the noise which was a difficulty at the beginning, greatly diminished".

The participants also reported that they developed reflective processes through action research. It is clear from the responses of teacher A, that she developed a reflexive process. She said: "If I had done something new in my class, I started thinking if it worked well, if I could improve it. I kept it in my mind and we discussed it at our meetings. Everything that was mixed up in my head started making sense".

Also teacher E. pointed out the importance of reflection, by saying that "the formation of such a group helps teachers, beyond educational matters, in reflection as well. So she had the opportunity to "think differently". She admitted that the results of reflection would be more effective if she kept a diary. "The diary seems important but I rarely kept it. I think that if you observe, it's better to write down your thoughts, your weaknesses and students reactions in the diary. But I think that I am not very systematic". She stressed that the reason teachers do not keep a diary is because "we are not used to keeping a diary".

Teacher N pointed out that "through the discussions with colleagues she was led to reflection". But generally, she saw reflection as something difficult, perhaps because, she was not accustomed to such procedures. So she prefers "discussion with colleagues". She stated that "personally I can not think and write down my thoughts and feelings easily".

Teacher Mer. said that by the end of the meeting, she views some things differently: "I see that I can think of my teaching process at the end of the day".

We found out generally, that although reflection is a difficult experience according to the participants, some steps were made.

Beyond the reflective process, the third element mentioned by the participants that facilitated some changes, was the encouragement by the support group, the faculty member of the University and the facilitator (researcher). More specifically, the presence of the facilitator at school and the observation in classrooms according to the teacher Mer, was seen "as a second perspective, a second opinion, an opportunity for discussion". So she thinks she "is more creative now". The same view was shared by teacher N., who found the contact with the University very important. She said: "I found the contact really important".

Moreover, teacher A. pointed out that the presence of the facilitator in the classroom "strengthened the effort to change and work cooperatively, because there was a second opinion". She wondered, how often she would have a similar support and suggested timidly: "that the school advisors should organize and support groups at school". The same view was shared by teacher E.: "schools advisors could abandon theory and proceed in practice". On the contrary, teacher M. said that: "only people from Universities or researchers could stand next to the teachers".

In conclusion, the training effort within the school focusing on teachers' needs appears to have enhanced teachers' work and helped them introduce innovations and new teaching practices.

\subsection{Students'Attitude towards New Practices (Teachers' Point of View)}

Teachers' changes in their teaching process influenced their students, according to the participants. Their students' participation improved, their relations became better and the general climate in the classroom was more pleasant. According to teacher N., some students said: "we work as a group and we have a good time at school" and she pointed out that "the students became best receivers. They participate in choosing the topics and create a more pleasant atmosphere in the classroom". The teacher continued saying that the students are very satisfied with the new teaching approach. "When I dare to return to a teacher-centered lesson the students seem to be bored".

Teacher A said that her changes affected her students positively. She stressed that "by applying new practices, children's self-esteem is stimulated and the cooperation within the groups is satisfactory. The children were liberated. They learned to work together so well that when I enter in classroom, there is no need of special guidance or instructions to the groups. Everything seems to have been put on an autopilot".

It was also noted by the participants that interpersonal relationships among students ameliorated. Teacher Mer told us that "students seem to collaborate, to develop ideas to interact and respect other students' opinions". Teacher M. remarked "improvement of children's' relationships". Teacher E also pointed out that students through this new approach "had the opportunity to evaluate themselves and what happens among them", when she asked them to write about changes in their relationships. Generally, she observed "a good mood and the students did their best to participate in the group".

\subsection{Change of Teachers' Bond}

Beyond changes in relationships among students, the Beyond changes in relationships among students, the process of action research affected teachers' relationships as well. According to what Mer said: "We became a group 
that learned to discuss and communicate effectively".

Moreover, teacher N. reported that "a different bond has developed within the team this year. We have time for talking about teaching and pedagogical issues beyond our working hours. We would like to continue cooperating next year and attract other colleagues in the team".

Teacher A., although she was the only teacher from the other school unit and she did not know the other three teachers, said: "I felt comfortable in the group. I could feel relaxed and talk about everything. That's why we bonded as a team. I would like to transfer this collaborative spirit to my school".

\section{Conclusions}

It is evident that collaboration among teachers had an effect on their communication. Teachers exchanged ideas, expressed themselves without hesitation and adopted innovations.

The question that arises is, whether the team will continue this cooperation without the researcher's presence. Also, it would be desirable, the spirit of collaboration to be spread among the rest of their colleagues.

In conclusion, having the role of the facilitator within both the training sessions and in the classrooms as well, I noticed that participating in the collaborative process through interaction, a broader experimentation was achieved, new ideas were exchanged and reflection was developed as well.

It is obvious, however, that the implementation of the collaborative approach requires more preparation, more time available for carrying out the work and more patience because of the conflicts within groups. As a facilitator, I observed in classrooms, that children's attitude towards collaborative approach was positive. Gradually, students' interpersonal relationships were improved, especially in large classes, while it was more difficult with younger students.

Based on the above and on other researchers' as well [1, $15,20,24]$, it is more effective, teachers' training focuses on their needs, to take place at their own school, while educators, either University members or school advisors could undertake this complex and support work.

Therefore, we believe that with any effort we could support and enhance teachers' hard and lonely work. It could help them to change the traditional classroom, not only on paper, but in reality, transforming it into a modern school environment with priority in active, experiential and collaborative learning.

\section{Acknowledgements}

Kapachtsi Venetia and Kakana Domna thank warmly the five teachers of the two school units - Neli Aidona, Aspa Vafopoulou, Meropi Matzarli, Eleni Spanopoulou and Mary Stilidou- and the headmasters Christos Zouzoulas and Rigas Lemonis for the cooperation we had. Infact, we could do nothing without teachers' participation and headmasters' good will.

\section{References}

[1] Ambrose, D., Lang, K. \& Grothman, M. (2007). Streamlined reflective action research for creative instructional improvement. In Educational Action Research, 15, (1), pp. 61-74.

[2] Angelides, P., Evangelou, M. \& Leigh, J. (2005). Implementing a collaborative Model of Action Research for Teacher Development. In Educational Action Research, 13, pp. 275-290.

[3] Bagakis, G, Demertzi, K, \& Stamatis, Th (ed.) (2007). A School Learns. Self-evaluation of a school under the program Carpe Vitam. Leadership for Learning [in Greek]. Athens: Livani.

[4] Bagakis, G. (2005). Self-assessment of the school unit. From the work of Joseph Solomon on current efforts in Greece and beyond [in Greek]. Athens: Metaixmio

[5] Bustingorry, S.O. (2008). Towards teachers' professional autonomy through action research. In Educational Action Research, 16, (3), pp. 407-420.

[6] Calhoun, E.F. (1993). Action research: Three approaches. In Educational Leadership, 51, (2), pp. 62-65.

[7] Caro- Bruce, C. \& McCreadie, J. (1994). Action Research in one School District. In Elementary School Journal, 95, (1), pp. 33-40.

[8] Carr, W. \& Kemmis, S. (1986). Becoming Critical: Education, Knowledge and Action Research, London: Falmer Press.

[9] Carr, W. \& Kemmis, S. (1997). For a critical educational theory. Education knowledge and action research, [in Greek] (A. Lampraki-Paganou, transl.). Athens: Kodikas

[10] Christenson, M. (2002). The rocky road of teachers becoming action researchers. In Teaching and Teacher Education, 18, pp.259-272.

[11] DEPPS (2003). Greek Cross Thematic Curriculum Framework for Compulsory Education (issue B, nr 303/13-03-03 \& 304/13-03-03) [in Greek]. Pedagogical Institute http://www.pi-schools.gr/programs/depps/

[12] Didahou, E., Bagakis, G., Loumakou, M., Pomonis, M., Valmas, F. (2009, November). Teachers' self-education and professional development: An example through cooperation between preschool and primary teachers on children's transition. Paper presented to the 33rd Collaborative Action Research Network (CARN) International Conference, Athens.

[13] Emmer, E. T., \& Gerwels, M. C. (2002). Cooperative learning in elementary classrooms: Teaching practices and lesson characteristics. The Elementary School Journal, 103, 75-91.

[14] Giroux, H. (1992). Border Crossings. Cultural Workers and the Politics of Education, New York, Routledge.

[15] Helstad, K. (2009, November). Teacher learning at the Workplace. In what ways do expert participants contribute to the processes of knowledge building. Paper presented to the 33rd Collaborative Action Research Network (CARN) International Conference, Athens. 
[16] Iosifides, Th. (2003). Analysis of qualitative data in the social sciences [in Greek]. Athens: Kritiki Publishing.

[17] Johnson, D.W., Johnson, R.T., \& Stanne, M.B. (2000). Cooperative learning methods: A meta-analysis. Retrieved from May 25, 2013, http://www.tablelearning.com/uploads/File/EXHIBIT-B.pdf

[18] Joyce, B. (1991). The doors to school improvement. In Educational Leadership, 48, (8), pp. 59-62.

[19] Kakana, D.M. (2008). Collaborative teaching and learning: Theoretical approach and educational prospects [in Greek]. Thessaloniki: Kiriakidi Bros.

[20] Kakana, D.-M. \& Botsoglou, K. (2010). In-service teacher's reform from the traditional model to cooperative teaching and learning through the process of action research In D. Germanos \& M. Kanatsouli (ed.), Modern Pedagogical Approaches in preschool and primary school education, [in Greek]. Thessaloniki: University Studio Press

[21] Kapachtsi, V. (2011). School unit self-evaluation. A developmental process, [in Greek].Thessaloniki: Kiriakidi Bros.

[22] Kemmis, S. (2006). Participatory action research and the public sphere. In Educational Action Research, 14, (4) pp 459-476.

[23] Kemmis, S. (2009, November). What is to be done? The place of action research. Paper presented to the 33rd Collaborative Action Research Network (CARN) International Conference, Athens.

[24] Lally, V. \& Scaife, J. (1995). Towards a Collaborative approach to Teachers' Empowerment. In British Educational Research Journal, 21, (3), pp. 323-337.

[25] MacBeath, J. (2001). The school self-evaluation. Utopia and practice. (Ch. Doukas \& Z. Polimeropoulou, tranl. In greek) [in Greek]. Athens: Ellinika Grammata.

[26] MacGilchricst, Barbara, Myers Kate. \& Jane Reed (2004). The intelligent school. Sage Publications

[27] Mason, J. (2003) Conducting qualitative research (ed. N. Kiriazi) [in Greek]. Athens: Ellinika Grammata.

[28] Matsaggouras, E. (2005). Professionalism and profession development. In G. Bagakis, (ed). Training and professional development of the educator, [in Greek]. Athens: Metaixmio.

[29] Milovic, S. \& Cain, T. (2009, November). Action research as a tool for professional development of advisers and teachers in Croatia. Paper presented to the 33rd Collaborative Action Research Network (CARN) International Conference, Athens.

[30] Salleh, H. (2006). Action research in Singapore education: constraints and sustainability. In Educational Action Research, 14, (4), pp. 513-523.

[31] Smylyan, L. (1987). Collaborative Action Research: A Critical Analysis. In Peabody Journal of Education, 64, (3), pp. 57-70.

[32] Vermeulen, D., Tordoir, A. \& Kroon, H. (2009, November). Double loop learning in the Double Loop of Action Research School improvement as action Research. Paper presented to the 33rd Collaborative Action Research Network (CARN) International Conference, Athens. 